Andrea A. Coles and William Dougherty

\title{
Hang together or hang separately Improved information services through communication and culture
}

$\mathbf{T}$ he interdependence between information science and information technology is inherent in the interplay of each fields' related professions. If we use a loose definition of the term systems, we could consider the relationship between libraries and information technology departments as a system. ${ }^{1}$ Since both groups are involved in providing access to and disseminating information, the term information systems is warranted in this context. This library-IT system exists to connect people with data and information, resulting in information services with the term services reflecting the mission or raison d'être for both entities. Whether your library and IT departments have merged completely, function as separate entities, or manifest one of the popular Facebook status choices, "It's Complicated" or "In an Open Relationship," daily realities of dysfunction and misunderstandings may often prevail.

Having worked in each others' academic library and information technology worldswith William Dougherty transferring from a system administrator management position in a library environment to a similar position in a strictly information technology department and Andrea Coles moving from information management in an IT environment to an academic electronic resources librarian position-we share a full appreciation and understanding of the issues and people involved in both arenas. We see firsthand how these two worlds interweave and affect one another. We have experienced the fruits of good, and the frustrations of poor, communication. We know the satisfaction of understanding each others' goals and the discouragement when misunderstood by our counterparts. At best, what were once clear duties and job descriptions have melded into a harmonious mix of talents and interests, or, at worst, a hornet's nest of conflicting goals. With Baby Boomer librarians and information technologists retiring from the workforce, Generation Jones ${ }^{2}$ and Generation X are here to take their place as the establishment leading the way for the ascendancy of Generation Y. As both of us hail from the anonymous, overshadowed, in-between Generation Jones age group, we think it apropos for us so-declared tech-savvy Jonesers $^{3}$ to speak out to overcome disconnects in our working relationships and lead "from the middle through influence." ${ }^{\text {C Con- }}$ tinuing to act in a way that provides services in a separate, à la carte, fashion may not only be detrimental to patrons and end-users, but will not benefit either profession in the long run.

When we think of various successful projects accomplished in collaboration between librarians and IT personnel and why they actually produced positive outcomes, two underlying themes consistently arise: communication and culture. Somerville, Schader, and Huston, in their article "Rethinking what we do and how we do it: Systems thinking strategies for library leadership," 5 explain well how critical these two parts of working relationships are:

Andrea A. Coles is electronic resources librarian at King College in Bristol,Tennessee, e-mail: aacoles@king.edu, and William Dougherty is assistant director for systems support at Virginia Tech, e-mail: william@vt.edu

๑) 2009 Andrea A. Coles and William Dougherty 
"In our research, we consider culture and communication together because, for organisational members to communicate and cooperate, they must share enough [emphasis ours] common assumptions and standards, sufficiently representative of social reality, to make aligned judgments and actions possible. Therefore, 'culture', in this sense, consists of a shared basis of appreciation and action developed through communication within an organisational system."

In building a productive relationship between information technologists and librarians, the success we have personally experienced sprang from acting on the following principles of communication and culture.

\section{Communication}

In order to produce, collect, distribute, and protect information and effectively communicate it to people, information technologists and librarians must stay mindful of the interconnectedness of technological systems. Effective communication to the masses is a reflection of effective communication behind the scenes. For example, when IT must shut down a system for maintenance or repair, timing is important and it may affect technology applications in the library.

But how can we establish the foundation for communication between ourselves beforehand so that we are ready, not only during a crisis, but on a day-by-day basis? We suggest the following may help:

Realize and understand the basic social nature of information services. Information services are based on sharing, social exchange, and social networking. Specific measures to take that will make the most of this social nature are to:

- Ensure face-to-face and frequent interactions. ${ }^{7}$ Working together in a typical cubicle environment automatically provides frequent opportunity for interactions; however, if you are in a more traditional environment where your IT department may not even be in the same building as your library, everyone must make the effort to go out and make face-to-face connections. Maintain an open door philosophy so people feel welcome to approach you or visit your office. Communications can also be maintained through instant messaging, electronic lists, blogs, or other online tools.

- Encourage dialogues, rather than monologues, in conversations. Be mindful that conversations with your colleagues are give-and-take, rather than one-way lecturing. Somerville, Schader and Huston ${ }^{8}$ assert that dialoguing "improve[s] decision-making and coordinated action" - the very thing we need both in working toward our goals and in immediate emergency situations. For example, rather than saying "We have to have this piece of equipment," saying "We need to solve this problem. What would you recommend?" opens dialogue and invites participation in the process. Seeking advice from both groups when making technology decisions is not only wise, but can also be an effective way to gain buy-in. This can be as formal as officially meeting to discuss the matter at hand, or can result in informal conversation and impromptu brainstorming.

- Collaborate on projects with your IT counterparts. Of course there will be the obligatory projects or committees; for example, documenting helpdesk instructions and information for the knowledge base and Web site in the IT department at Virginia Tech initially "forced" IT staff to collaborate and communicate with the content editors and writers. We often were faced with clarifying, defining, and clearing up issues at a number of different levels through dialoguing before we could finalize what would actually be published. Over time, we found that as IT professionals reaped the benefits of required documenting and communicating clearly, particularly in helping people help themselves, they became more willing to initiate collaboration with the information specialists. Are there tasks, presentations, or other endeavors that your IT specialist will voluntarily partner with you in pursuing? 
- Be creative in building a social network between the library and IT. In order to strengthen the quality and flow of information and knowledge, think about the individuals involved and what might facilitate communication and cultural understanding. Spontaneity and fun might be called for occasionally. Chocolate and coffee, anyone?

Define roles if you can and embrace ambiguity when you cannot. If your library staff have varied IT skills, you may need to make it clear who is responsible for what, in order to avoid confusion with IT professionals. Clearing up blurry boundaries, and becoming comfortable with those that remain fuzzy, is akin to the adage "change what you can, accept what you cannot, and ask for wisdom to know the difference." Clarify roles when possible (who solves which technical issue?) and accept and even embrace those that are not as clearly definable (who manages the course management system? who should worry about digital copyright and at what level?).

\section{Culture}

During the communication process between library and IT personnel, it will become evident whether there are "enough common assumptions and standards" in your work environment. To us, that is one of the points of communication: establishing assumptions and premises so that we can understand and appreciate our differences and come to common ground on essential issues. Since assumptions and standards reflect our cultures, what can we do to bridge gaps in our IT and information services worlds? We suggest the following may help:

- Establish common goals and values. Whether goals are long-term and strategic or short-term and associated more with individual needs, when an institution can identify and communicate these goals effectively, everyone benefits. This may mean taking time to deliberate over goals and values, making an effort to build a stronger platform on which to establish "shared meanings."10 For example, as an institu- tion, you may decide the open source movement reflects your basic values and therefore affects your goals and strategies. Building on genuine shared meanings and goals may inspire both librarians and IT staff to a "commitment to something greater than an individual career" and a "devotion to the bigger idea," words used by Gjelten \& Fishel ${ }^{11}$ to describe characteristics of potential leaders.

- Stay relevant. As IT staff begin to more fully participate in the instructional and research mission of higher education institutions, interaction with and knowledge of skills possessed by library professionals can help bridge any gaps that exist between technologist and patron. Librarians and other information professionals are the natural link between IT and end-users with the advent and ascendance of digital collections and repositories, wikis, social networking tools such as Facebook, and blogs. Technological and social issues-such as solving the challenge of storing massive digital collections, which are increasingly becoming graphic and audio/visual, so they can be retrieved ten, twenty, or even one-hundred years from now-must be faced together.

- Respect and appreciate each others' strengths. Once you have defined roles and accepted necessary blurry boundaries, librarians and IT staff would do well to be mindful of respecting and appreciating each other's area and strengths. ${ }^{12}$ For example, in the academic library environment, IT staff may have the technical savvy to access data or fix issues that librarians may not, while a librarian may have the political contacts or acumen to relate to faculty members that IT personnel may not. ${ }^{13}$ As we appreciate each of these positions and are content with our roles, we can work more effectively together to help patrons and end-users access information and data.

- Offer consistent closure and follow through. Being dependable and following through can cover a multitude of sins. While other aspects of communication and culture are important, being consistent and steady in bringing closure to projects and making decisions in a timely manner is a cornerstone in building better trust and smoothing work relationships. ${ }^{14}$ 
- Like each other ... or at least maintain collegial attitudes. When librarians and IT professionals genuinely like each other, obviously the work atmosphere will be at least pleasant, hopefully more productive, and a positive work culture can grow. Of course, reality shows that we cannot expect to be kindred spirits with everyone, but we can strive to create and maintain collegial relations by appreciating our differences and one another's contributions. Making an effort to find common ground whenever possible can help bridge interpersonal interactions.

\section{Conclusion}

It is the usual goal of professionals to be constructive and make a contribution to their respective professions. Some may even make an extra effort to foster cooperation with their peers and ensure their constituents are served well. Long-term benefits of contributing to the common good and increasing the effectiveness of their business, whatever that business may be, can be realized. As librarians and information technologists, we must join together to share our tacit and explicit knowledge in order to put and keep the pieces of the information access puzzle together.

Speaking from our GenJonesers' perspective, caught in-between Boomer idealism and Gen X cynicism, "we're Jonesin' for our brand of realistic idealism to be heard."15 We believe better coordination of our services can be achieved if we follow the aforementioned principles of communication and culture: embracing the social nature of information services, defining roles and being patient with blurry lines, establishing common goals and values, remaining relevant, while grounding all of this in respect and appreciation for each others' strengths. As a natural outcome of ameliorating the cycle and dynamics of relationships, our collegial attitudes will flourish and a better trust can be established. Forbearing and enduring with one another when mistakes happen and keeping the larger vision and common goals in mind, as Benjamin Franklin implored in 1776, "we must all hang together, or most assuredly we shall all hang separately"!

\section{Notes}

1. Lorri Zipperer and Sara Tompson, "Systems Thinking: A New Avenue for Involvement and Growth," Information Outlook, 10 no. 12 (2006): 16-20.

2. "Generation Jones" begins around 1954 , and cuts off at 1965, where "Generation X" begins. That places "GenJones" members in the 42 to 53 age range. See Ian Christopher McCaleb, "Overshadowed generation prepares to steer political agenda, author claims 53 million members of 'Generation Jones' ready to speak on their own" on CNN.com. (March 5, 2000). Retrieved January 14, 2009, from archives.cnn.com/2000/ALLPOLITICS /stories/03/05/generation.jones/index. html.

3. Tony Maciulis, "Keeping up with the Joneses: They're tech-savvy, and they may decide the election" on MSNBC.com. (November 6, 2006). Retrieved January 14, 2009, from www.msnbc.msn.com/id/15592086.

4. Mary M. Somerville, Barbara Schader, and Malia E. Huston, "Rethinking what we do and how we do it: systems thinking strategies for library leadership," Australian Academic \& Research Libraries, 36 no. 4 (2005): 214-27.

5. Ibid.

6. Ibid.

7. Maija-Leena Huotari and Mirja Iivonen, Trust in Knowledge Management and Systems in Organizations (Hershey: Idea Group Publishing, 2004).

8. Somerville, Schader, and Huston.

9. Ibid.

10. Ibid.

11. Dan Gjelten and Teresa Fishel, "Developing leaders and transforming libraries," CERL News, 67 no. 7 (2006).

12. Huotari and Iivonen.

13. Robert E. Renaud, "Shaping a New Profession: The role of librarians when the library and computer center merge," Library Administration \& Management, 20 no. 2 (2006): 65-74.

14. Huotari and Iivonen.

15. Greg Siegle, "Some Call It 'Jones'” in the Washington Post, (April 6, 2000). $n$ 